\title{
Erratum to: Cost-effectiveness of febuxostat in chronic gout
}

\author{
Stephen M. Beard • Birgitta G. von Scheele • \\ George Nuki · Isobel V. Pearson
}

Published online: 18 June 2014

(c) Springer-Verlag Berlin Heidelberg 2014

\section{Erratum to: Eur J Health Econ (2014) 15:453-463 \\ DOI 10.1007/s10198-013-0486-z}

In the original publication, the size of cohort was incorrectly published as 1,000 patients in the first sentence of the fourth paragraph under heading 'Methods'. The correct cohort size is " 100 patients" and the sentence should read as:

"The model was used to consider a cohort of 100 patients who had sUA levels of at least $8 \mathrm{mg} / \mathrm{dl}$ $(0.48 \mathrm{mmol} / \mathrm{l})$ and who had received a ULT with various treatment sequences".

The online version of the original article can be found under doi:10.1007/s10198-013-0486-z.

S. M. Beard

RTI Health Solutions, Sheffield, UK

B. G. von Scheele

RTI Health Solutions, Lund, Sweden

G. Nuki

Institute of Genetics and Molecular Medicine, University of

Edinburgh, Western General Hospital, Edinburgh, UK

I. V. Pearson $(\square)$

RTI Health Solutions, 2nd Floor, The Pavilion Towers Business

Park, Wilmslow Road, Didsbury, Manchester M20 2LS, UK

e-mail: ipearson@rti.org 